\title{
IMPACT OF UPFC ON THE POWER QUALITY IN GRID
}

\author{
Puneet \\ Assistant Professor, \\ Guru Nanak Dev Engineering College, \\ Ludhiana, Punjab, India
}

\begin{abstract}
To reduce the complexity and improving effectiveness of power system UPFC is one of the most effective and reliable device. In this impact of using UPFC is studied for the model grid prepared using MATLAB having two generators and one major load centre. The flow of active and reactive power, voltage stability and fault recovery time is studied for this model whose results are given by the MATLAB Simulink. The results clearly show the improvement in power quality in grid at system and load buses and also improvement in other various factors has been observed.
\end{abstract}

Keywords: FACTS, UPFC, STATCOM, SSSC, Active and Reactive Power

\section{INTRODUCTION}

These days the operation of power system is very complex due to which some problems can be noticed while transmitting power from one zone to another. Some of these limitations are like short circuiting, oscillation in system, transient stability etc [1]. To eradicate these issues FACTS technology is found to be very efficient [2]. FACTS comprises power electronic equipments like GTO, thyristor and others which helps in effective utilization of power that can be transferred with maximum value over interconnected systems with proper control, reliability and improvisation. System stability can be either increased or decreased and it depends upon the control and optimum placement of FACTS controller [3]. By calculating the active and reactive power the steady state operation condition can be obtained [4]. UPFC is the device which had ability to control both the active and reactive power [5]. UPFC also can control the line parameters i.e. impedance, phase angle and voltage [6]. To transfer maximum power

\author{
Baljeet Singh \\ Assistant Professor, \\ Guru Nanak Dev Engineering College, \\ Ludhiana, Punjab, India
}

and taking proper control over active and reactive power UPFC is combined with the controller of STATCOM and SSSC is used in the system [7]. STATCOM is able to generate or absorb reactive power that can be independently controlled as it is a voltage source converter whereas SSSC is type of solid state voltage source inverter which can generate controllable AC voltage [8]. UPFC works on a condition that there should not be distortion in a sine wave of the source [9].

The aim of the present work is to improve the voltage profile and controlling real and reactive power for the stability of power system operation. For this purpose UPSC controller in combination with STATCOM and SSSC is used wherever STATCOM is employed for shunt controlling and SSSC for series attachment for control of line. Both of them provide active and reactive power support to the $\mathrm{AC}$ power system.

\section{UNIFIED POWER FLOW CONTROLLER}

For a high voltage power transmission network a UPFC quickly provides reactive power compensation. The current is allowed to flow through transmission line through the series transformer and for this purpose UPFC uses a three phase controllable bridges. The controller is able to control both active and reactive power through the transmission line. UPFC plays a key role in improving the transient stability and suppress oscillation in power system. UPFC is one of the most flexible and reliable controller that have been developed so far. These have all the capabilities of voltage regulation, phase shifting and series compensation. 


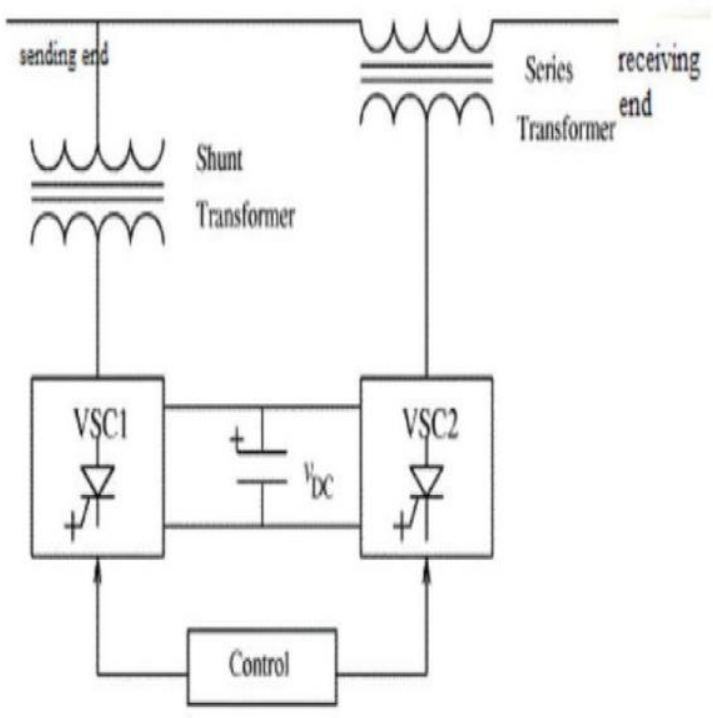

Figure 1 UPFC layout with VSCs

Figure 1 is representing UPFC having two VSCs connected through a single DC terminal. Out of two VSCs one is connected in shunt through coupling transformer and another one is in series to the transmission line through the transformer. DC power is made available by the capacitor bank connected to both converters. The real and reactive power is exchanges with the help of series converter and reactive is generated and absorbed internally also by the series convertor. Capacitor here generates and absorbs real power. The first shunt convertor derives real power from main supply and supply to feed the demand of second convertor. Shunt convertor also helps in maintaining the constant voltage across the bus.

\section{STATIC SYNCHRONOUS COMPENSATOR}

Static Synchronous Compensator (STATCOM) is shunt connected FACTS device. It is mainly used for reactive power control. In this work STATCOM is used to suppress voltage fluctuation to provide stable voltage. It is a DC-DC voltage VSC where DC capacitor acts as storage unit. Power electronic switches there are used to derive sinusoidal output from a DC source.

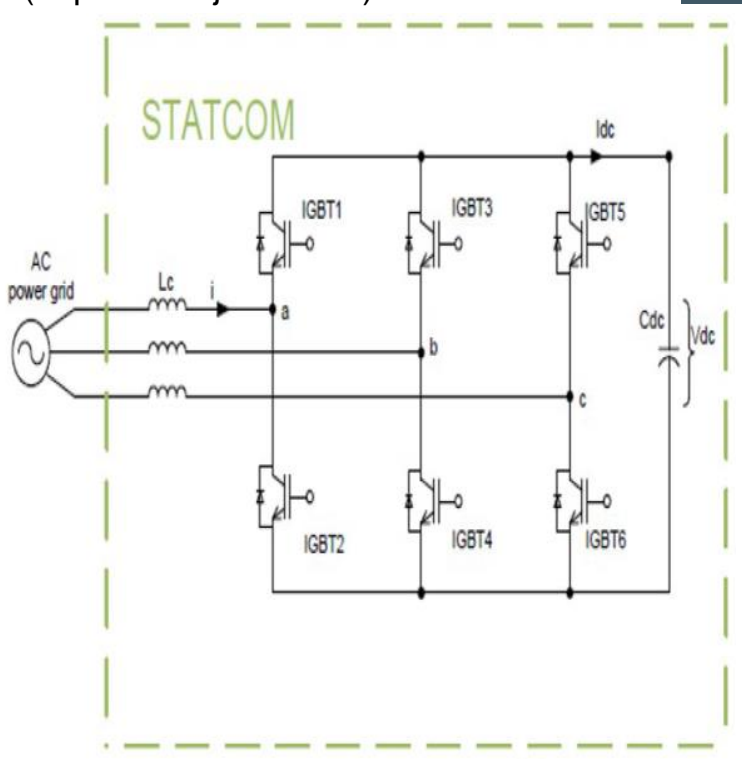

Figure 2 Circuit diagram for STATCOM

Here in this figure 6 IGBTs are there connected with anti-parallel diodes. AC power grid is connected to STATCOM by the coupling inductor $\mathrm{L}_{\mathrm{C}}$. By controlling phase and amplitude of output voltage of convertor, the exchange of real and reactive power can be controlled between STATCOM and AC grid

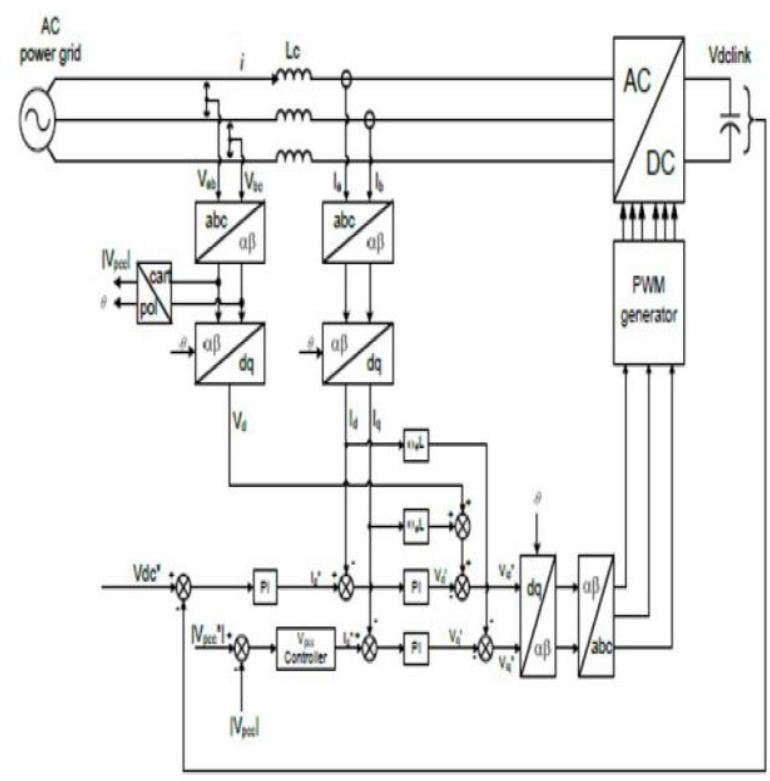

Figure 3 Control Design of STATCOM

Active and Reactive power flow can be directly controlled by controlling $\mathrm{d}$ and $\mathrm{q}$ axis components. For control there are three main loops for STATCOM i.e. inner current control loop, DC voltage control loop and PCC voltage control loops. 


\section{STATIC SYNCHRONOUS SERIES COMPENSATOR}

Static Synchronous Series Compensator (SSSC) is the FACTS based on Power Electronic device which act as a Synchronous Voltage Generator. These generate three phase AC voltage from DC source or capacitor bank in which voltage is phased in quadrature with the line current. These are installed in series with the line used for transmission with the help of series coupling transformer.

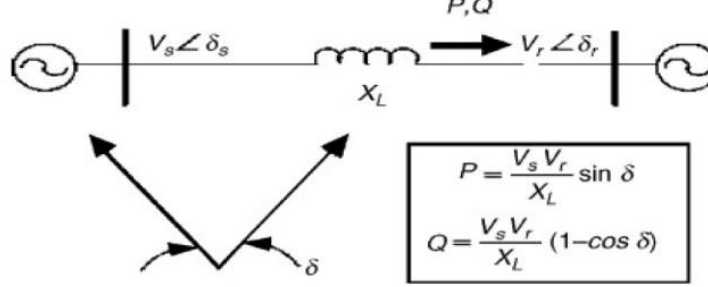

Figure 4 test system power transmission for sssc with sending and receiving end voltage

\section{PROBLEM FORMULATION}

In this work UPFC is initially connected between the buses. Firstly the results are checked with variation in the active, reactive power and voltage without using UPFC. Eventually results will be checked again after connecting UPFC in the system. In this work the system recovers time is also studied after the introduction of fault in system. The methodology is based on injecting the series voltage in quadrature with the transmission line and current allowing it to work same as to that of a variable series capacitor. By changing the magnitude of the series injected voltage which is in quadrature with the transmission line current, the real power flow can be controlled.

\section{RESULTS}

To verify the results MATLAB software is used. For analysis two 3-phase permanent magnet synchronous machines are modeled in dq rotor reference frame. Stator winding in this model is connected in wye to internal neutral point. Both synchronous generators have capacity of generating 2100MVAand 1400MVA active power respectively. The step up transformer of $13.8 \mathrm{KV} / 500 \mathrm{KV}$ is used here. The grid is having two power generating substation and one major load centre named located at bus B3. The load center of approximately $2200 \mathrm{MW}$ is modeled using a dynamic load model where the active $\&$ reactive power absorbed by the load is a function of the system voltage. The generation substation M1 is connected to this load by two transmission lines L1 and L2. L1 is $280-\mathrm{km}$ long and L2 is split in two segments of $150 \mathrm{~km}$ in order to simulate a threephase fault (using a fault breaker) at the midpoint of the line.

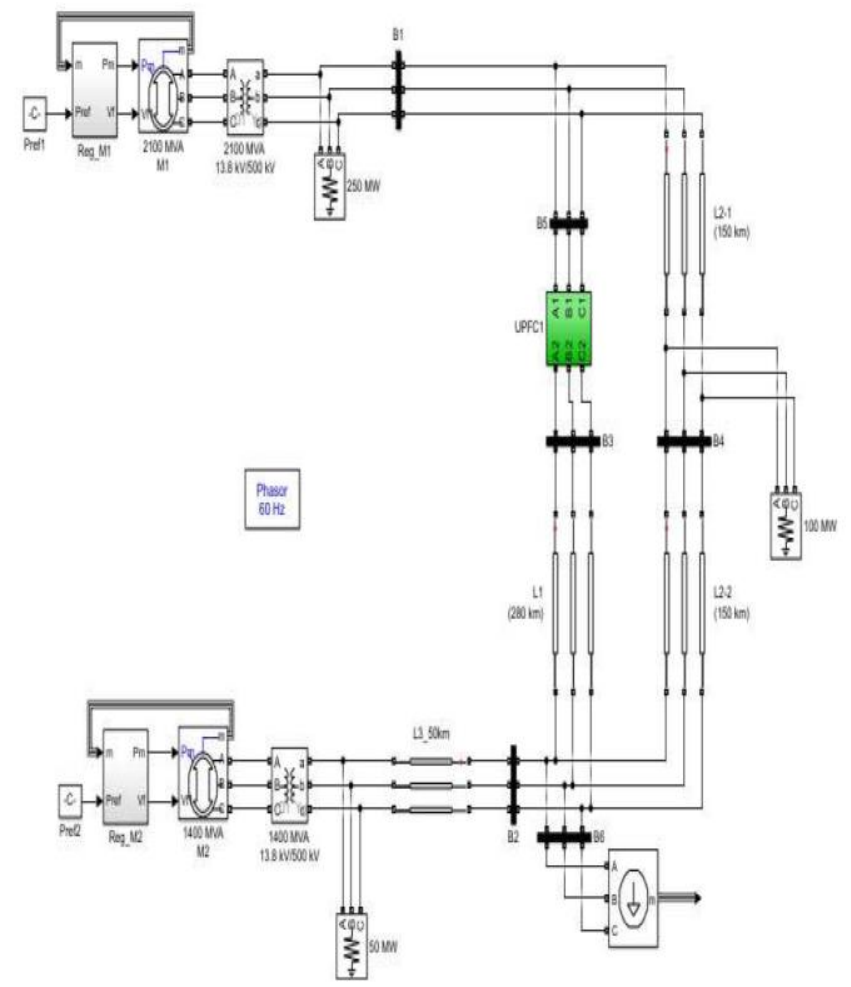

Figure 5 UPFC model with two synchronous generators

The MATLAB SIMULATION results are shown below.

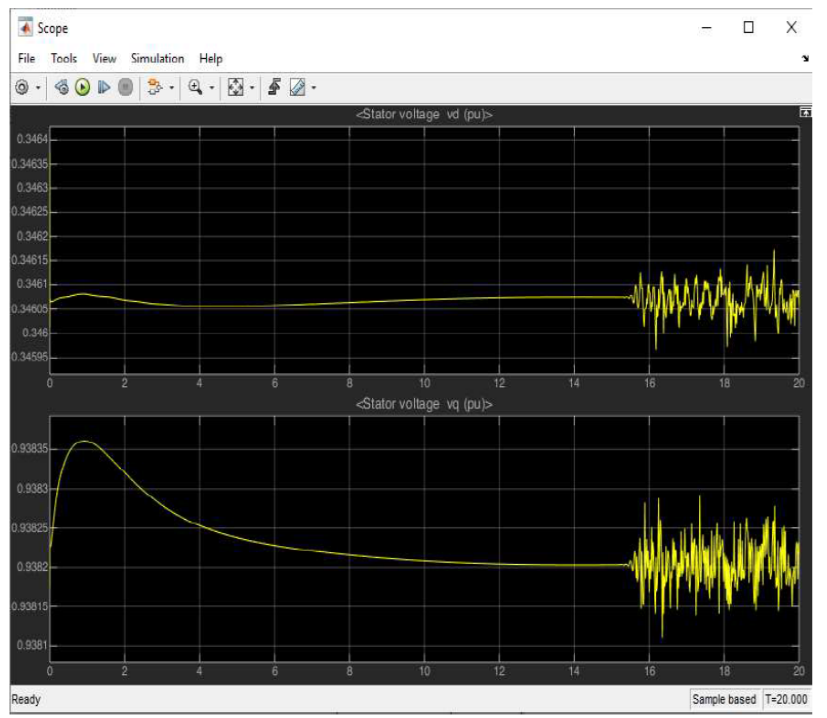




\section{International Journal of Engineering Applied Sciences and Technology, 2021}

Vol. 6, Issue 1, ISSN No. 2455-2143, Pages 319-324

Published Online May 2021 in IJEAST (http://www.ijeast.com)

Figure 6 Stator voltage $\left(\mathrm{V}_{\mathrm{d}}\right)$ stator voltage $\left(\mathrm{V}_{\mathrm{q}}\right)$ without using FACTS device

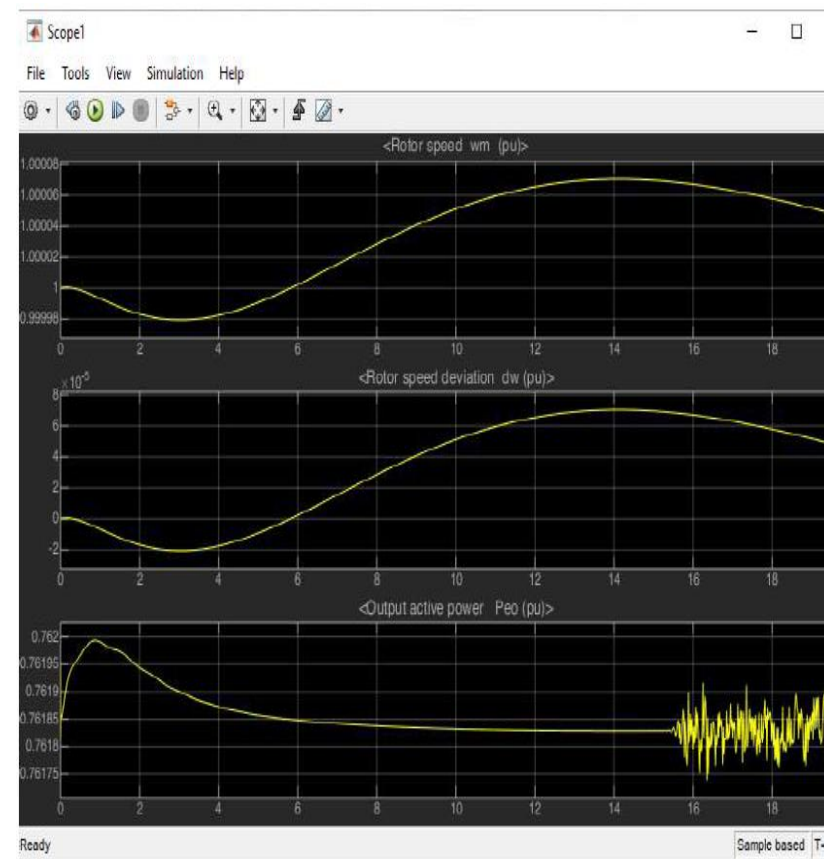

Figure 7 Rotor speed (wm) rotor speed deviation (dwm) output power

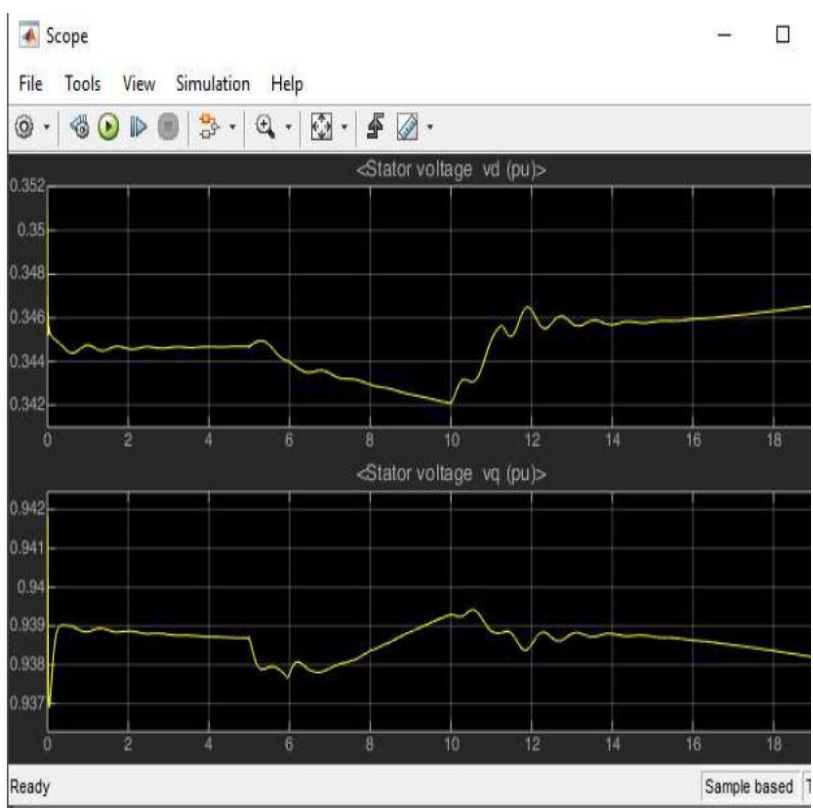

Figure 8 stator voltage $\left(\mathrm{V}_{\mathrm{d}}\right)$ stator voltage $\left(\mathrm{V}_{\mathrm{q}}\right)$ using UPFC
T. Sopet

File Tools Vim Sinulaion Helie

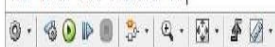

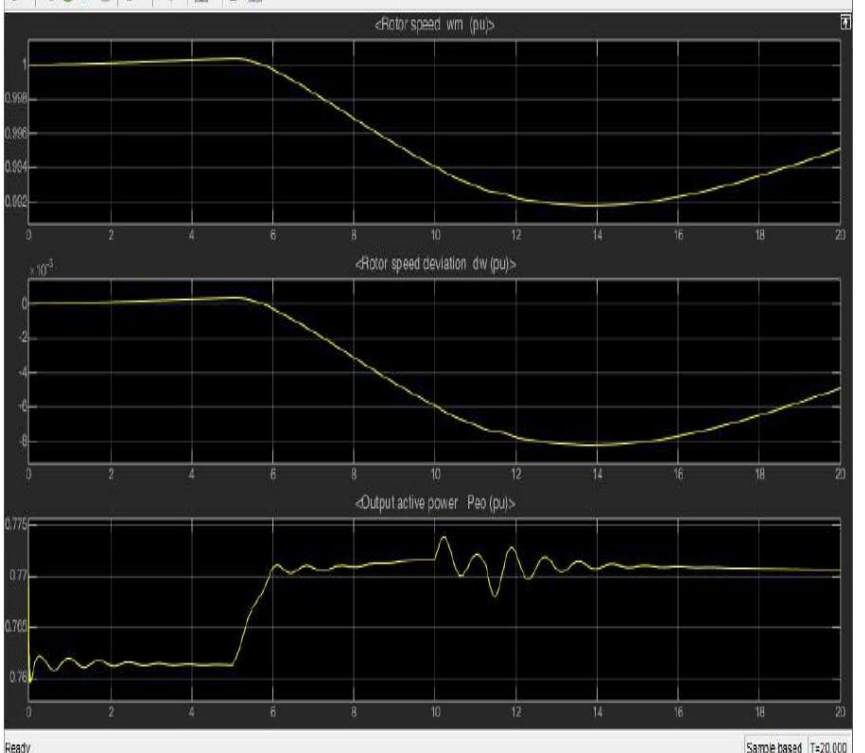

Figure 9 Rotor speed (wm) rotor speed deviation (dwm) output power using UPFC

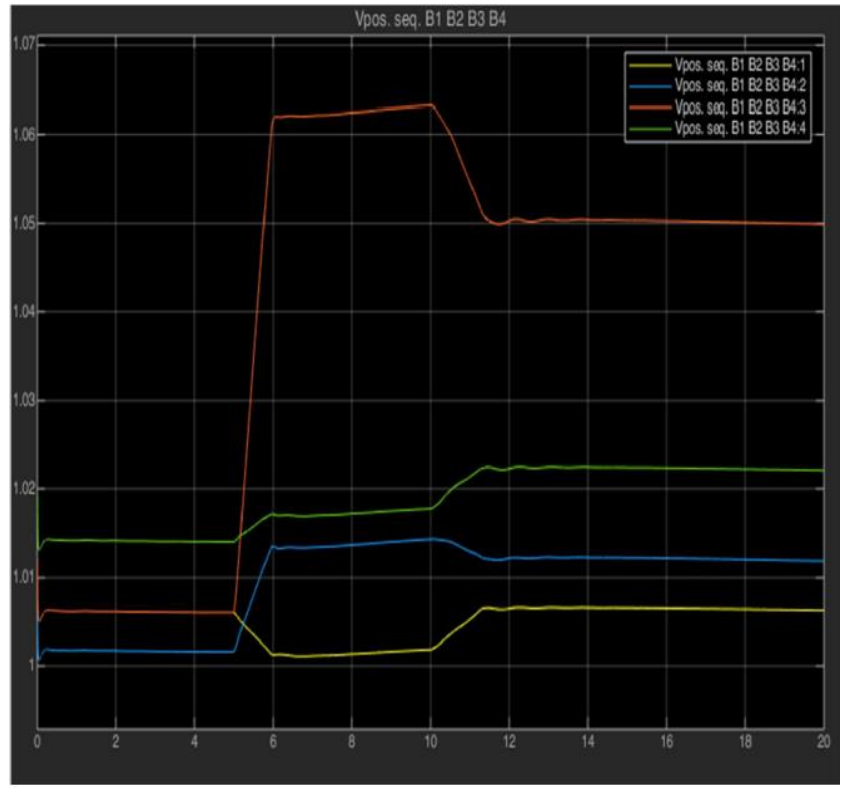

Figure 10 voltage (pu) using UPFC at buses b1, b2, b3, b4 
International Journal of Engineering Applied Sciences and Technology, 2021

Vol. 6, Issue 1, ISSN No. 2455-2143, Pages 319-324

Published Online May 2021 in IJEAST (http://www.ijeast.com)

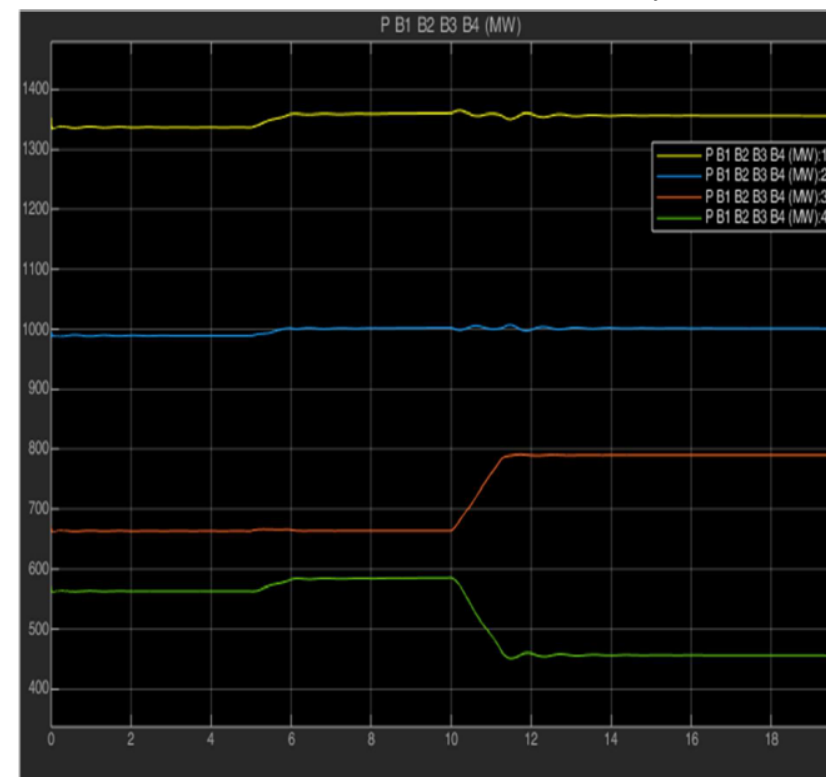

Figure 11 Active Power using UPFC at buses b1, b2, b3, b4 using UPFC

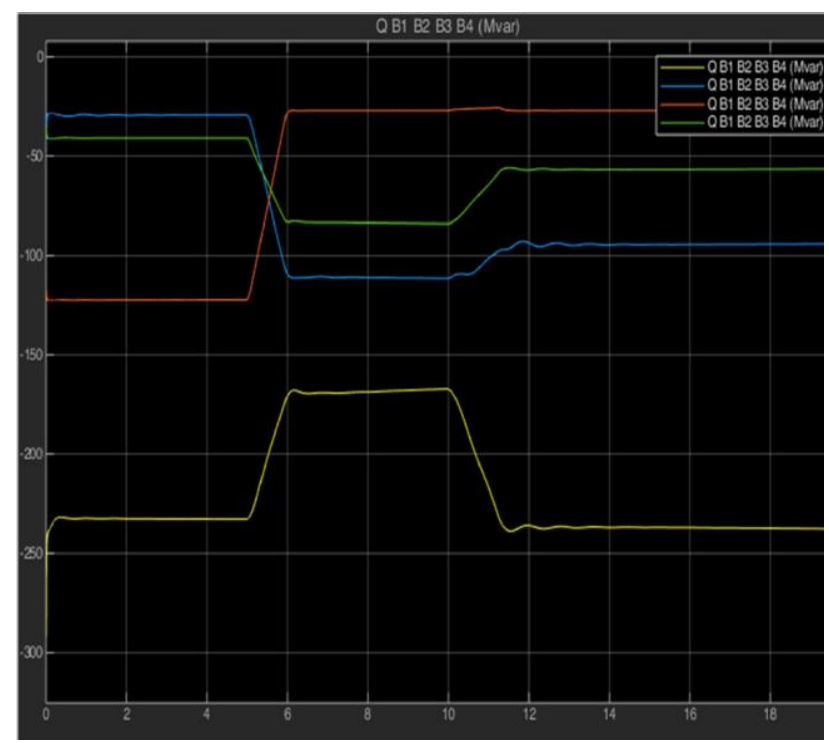

Figure 12 Reactive Power using UPFC at bus b1, b2, b3, b4

\section{CONCLUSION}

From the MATLAB Simulation the results for the performance of UPFC have been evaluated and are shown in results section of this paper. It is noticed that UPFC put impact on each of the factor discussed in this paper. It is also noticed that UPFC improved the active and reactive power of the bus and also contributed in damping the oscillations. The fault recovery time response is also better after using UPFC

\section{REFRENCES}

[1] Abrahamsson Lars (2017) "Considering risk in power system operation and the consequences of different accepted risk levels" ISBN 978-91-76732017-375 @ ENERGIFORSK

[2] Heinz K Tyll, Schettler Frank (2009) "Power system problems solved by FACTS" IEEE Power System Conference

[3] Singh Mithilesh, Gupta Shubhrata (2019) Optimal Placement of Facts Devices in Power System for Power Quality Improvement International Journal of Recent Technology and Engineering (IJRTE) ISSN: 2277-3878, Volume-7, Issue-6

[4] Nesci S., Gomez J.C. et al (2015) "Active and reactive power distribution under steady-state and transient conditions in doubly-fed induction generator (DFIG)" IEEE $17^{\text {th }}$ European Conference on Power Electronics and Applications

[5] Kuralkar Vaishali (2014)"Active and Reactive Power control using UPFC International Journal of Engineering Research and General Science" Volume 2, Issue 6, ISSN 2091-2730649

[6] Article by New York University on "UPFCis a combination of statcom and sssc" on coursehero webpage

[7] Saif. T. Fadhil, Ali Osman Arslan, Mete Vurual (2020) "Comparison of dynamic performances of STATCOM, SSSC, IPFC AND UPFC on inter-area oscillation dampping" The International Journal of Energy and Engineering Sciences, 5(2) 62-69

[8] Patel Manisha, Patel Divyesh S. et al (2017) "Reactive Power Compensation using STATCOM" International Research Journal of Engineering and Technology Volume 4 issue 4, Pg 564-567

[9] Beshir Abduselam Hamid (2019) "Control of Unified Power Flow Controller" University of Oviedo DOI:10.13140/RG.2.2.13084.54407

[10] Kumari Yogita, Gupta Anmol et al (2015) "Performance and Analysis of Reactive Power Compensation by Unified Power Flow Controller" Indonesian Journal of Electrical Engineering and Informatics (IJEEI) DOI:10.11591/ijeei.v3i3.153 
Published Online May 2021 in IJEAST (http://www.ijeast.com)

[11] Mishra Sanjay, Swain Sarat Chandra Tripathy L.N.(2017) "Fault Detection \& Classification in UPFC Integrated Transmission Line Using DWT" International Journal of Power Electronics and Drive Systems

8(4):1793DOI:10.11591/ijpeds.v8.i4.pp1793-1803

[12] Panigrahi Sindhuja, Panda Sibasish (2016) "Design and Analysis of Unified Power Flow Controller in Matlab/Simulink by using Fuzzy Logic" International Journal of Engineering Research \& Technology (IJERT)ISSN: 2278-0181 Vol. 5 Issue 05

[13] Singh Akshita, Ahmad Ameed Uddin (2015) "Control Reactive Power Flow with UPFC Connected Using Different Distance Transmission Line" International Journal of Advanced Research in Electrical, Electronics and Instrumentation Engineering Vol. 4, Issue 9

[14] Barua Ashutosh (2016) "Reactive Power Compensation using Unified Power Flow Controller" International Research Journal of Engineering and Technology (IRJET) Volume: 03 Issue: 05 